\title{
EXPERIMENTAL ANALYSIS OF BLENDED WING BODY MODEL MICRO AIR VEHICLE USING WIND TUNNEL
}

\author{
Md. Akhtar khan*1 \\ ${ }^{*}$ Assistant Professor, Department of Aerospace Engineering, GITAM School of Technology, Hyderabad, India \\ Chinmaya padhy ${ }^{2}$ \\ ${ }^{2}$ Associate Professor, Department of Mechanical Engineering, GITAM School of Technology, Hyderabad, India

\begin{abstract}
Ch. Sanjay ${ }^{3}$
${ }^{3}$ Former Distinguished Professor, Department of Mechanical Engineering, GITAM School of Technology, Hyderabad, India,
\end{abstract}

DOI: $\underline{\text { https://doi.org/10.36713/epra3794 }}$

\begin{abstract}
An experimental aerodynamic analysis is performed to obtain aerodynamic characteristics and performance of a blended wing-body aircraft (BWB) using Low Speed Wind Tunnel. The BWB design concept is a revolutionary way of understanding the hike of fuel cost, increase in air travelers and environmental concern. Recognizing the potential of the aircraft an experimental analysis is conducted on $B W B$ to understand aerodynamic performance parameters like lift coefficient (CL), drag coefficient (CD) and the Lift-to-Drag (L/D) ratio.The aluminium BWB model is manufactured using CNC machine and is tested in Wind tunnel at different angle of attack varying from $0^{\circ}$ to $16^{\circ}$ at speed of $12 \mathrm{~m} / \mathrm{s}, 25$ $\mathrm{m} / \mathrm{s}$ and $35 \mathrm{~m} / \mathrm{s}$ velocity. The present $B W B U A V$ design has achieved an unprecedented capability in terms of sustainability of flight at high angle of attack, low parasite drag coefficient and decent maximum lift coefficient. This study indicates some significant benefits for the $B W B$ relative to the conventional aircraft configuration.

KEYWORDS: Blended Wing Body (BWB), Aerodynamics, Unmanned Aerial Vehicle (UAV), Wind Tunnel
\end{abstract}

\section{INTRODUCTION}

The current design of transport aircraft has not changed significantly in the past few decades; rather incremental design optimization has taken place on each new generation of aircraft. BWB is a hybrid of flyingwing aircraft and the conventional aircraft where the body is designed to have a shape of an airfoil and carefully streamlined with the wing to have a desired planform. If the wing in conventional aircraft is the main contributor to the generation of lift, the fuselage of BWB generates lift together with the wing thus increasing the effective lifting surface area.

The aerodynamic lifting body shape between fuselage and wing intersections reduces interference drag, reduces wetted surface area which reduces the skin friction drag while the slow evolution of fuselage-towing thickness by careful design may suggest that more volume can be stored inside the BWB aircraft, hence, increases payload and fuel capacity The purpose of this research is to understand the aerodynamic performance and efficiency of BWB aircraft with respect to a conventional aircraft. .This concept aims at combining the advantages of a flying wing with the loading capabilities of a conventional airliner by creating a wide body in the center of the wing to allow space for passengers and cargo. Especially, for very large transport aircraft, the BWB concept is often claimed to be superior compared to conventional configurations in terms of higher lift-to-drag ratio and consequently less fuel consumption. The methodology used is the modeling of a 
BWB aircraft using CATIA software and fabricated subsonic wind tunnel. using $\mathrm{CNC}$ machine and then it is tested in the low

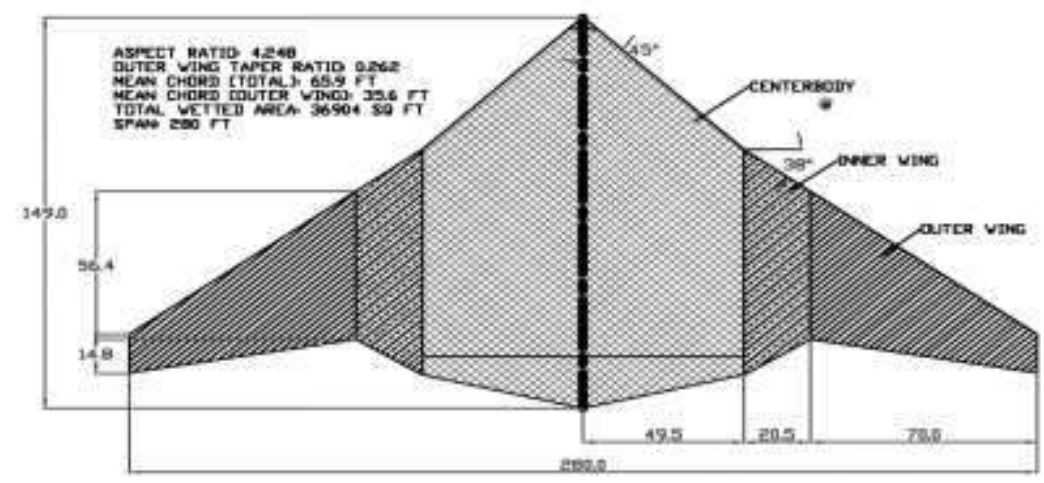

\section{DESIGN AND MODELING}

The BWB body is considered as the lifting body itself, where every aerodynamic parts will contribute for the lift production. In this BWB design did not include engines and were tested according to aerodynamic capabilities. The total span length of the aircraft is $280 \mathrm{ft}$ considered from left wingtip to right wing tip. The aspect ratio, which is the ratio of its span to its aerodynamic breadth or chord, is $4.248 \mathrm{ft}$. The outer wing taper ratio,

\section{Fig.1 Planform View of BWB}

which is the ratio of the chord at the tip to the chord at the root, is 0.262 . The total wetted area is 36,904 square feet. The scale used was 1:304. The first part which is modeled is the center body as shown in fig.2.1. The center body is the feature which makes blended wing body configuration unique. Not only does it house the payload, but it also generates lift.

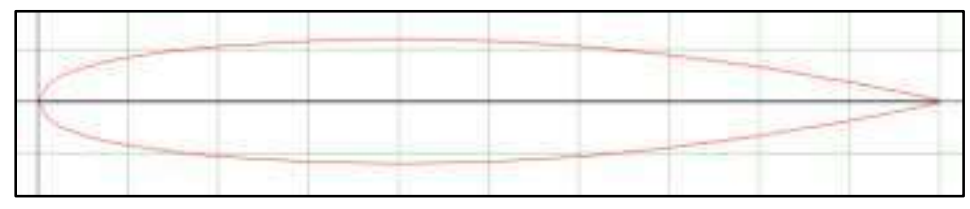

Fig.2 NACA 0012-64 airfoil (center body)

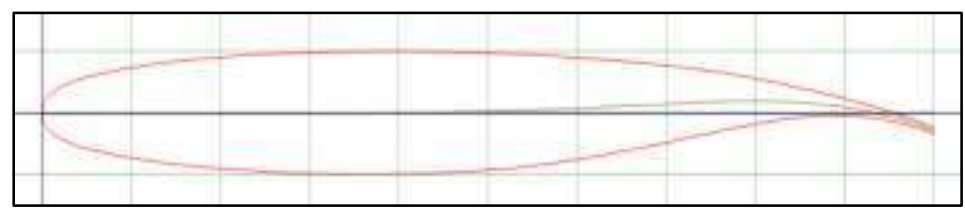

Fig.3 NACA SC (2)-0710 airfoil

The centre body section is designed with NACA 0012-64 airfoil as shown in Fig.2.which shows a closer view of the cross-section of the center body. The airfoil used for the wings is NACA SC (2)-0710 as shown in Fig.3. It is a supercritical airfoil. A supercritical aerofoil is an aerofoil for which the upper surface is flat and the lower surface is cusp shape lying at $60 \%$ of the chord.
A supercritical airfoil is an airfoil designed, primarily, to delay the onset of wave drag in the transonic speed range. Supercritical airfoils are characterized by their flattened upper surface, highly cambered aft section, and larger leading edge radius. 


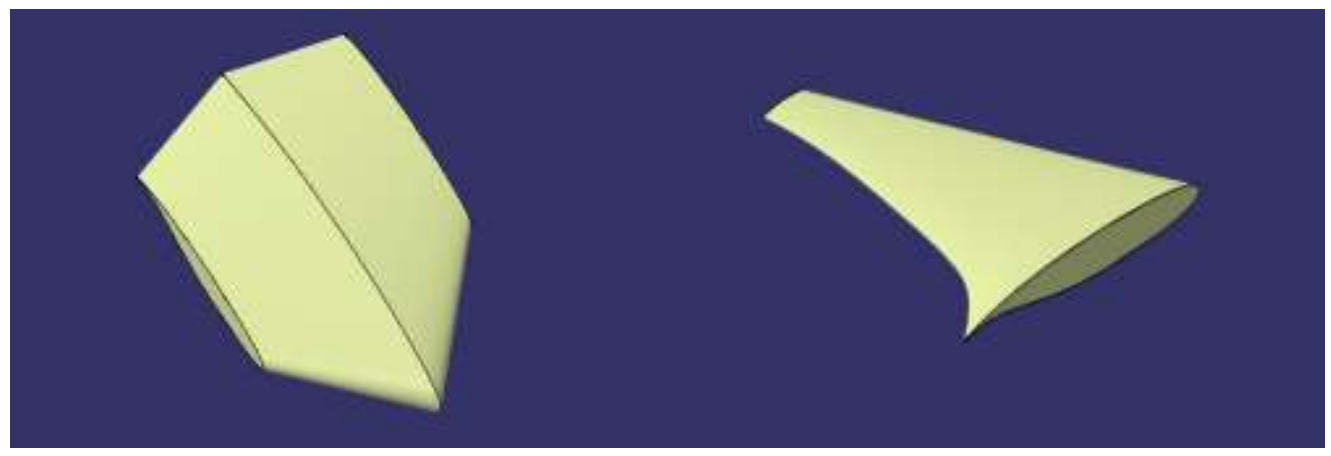

Fig.4 Blended wing body centre body and Wing

A winglet is a lift augmenting device which is attached at the wing tip of an aircraft. Winglets are used to improve the aerodynamic efficiency of an aircraft by lowering the

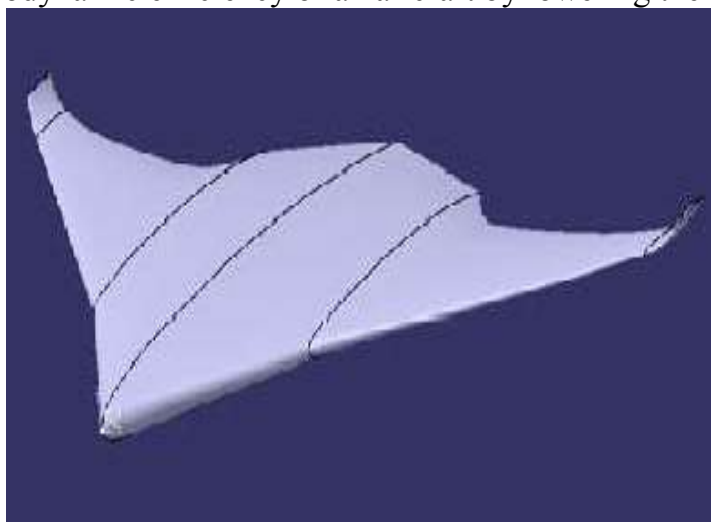

Fig.5 BWB aircraft CATIA model
Since, Fig. 5 shows the final model which has been designed for further analysis. The engines are not included in the design because the focus of this study is on the aerodynamic effect of the overall configuration of the aircraft. The model is manufactured using formation of induced drag which is caused by the wingtip vortices.

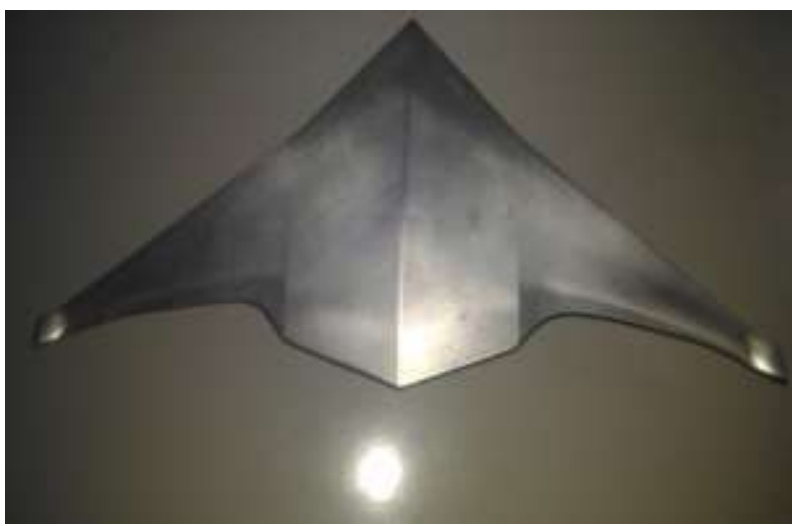

Fig.6 CNC Aluminium BWB Scaled model

Aluminium material in the $\mathrm{CNC}$ machining process as shown in Fig.6.The aerodynamic forces ,moments and Coefficients of forces and moment can be calculated using the below equations. The specification is shown in table 1 .

$$
\begin{gathered}
L=F_{y} \cos \alpha-F_{x} \sin \alpha \\
D=F_{y} \sin \alpha+F_{x} \cos \alpha \\
C_{L}=\frac{L}{\frac{1}{2} \rho V^{2} S} \\
C_{D}=\frac{D}{\frac{1}{2} \rho V^{2} S} \\
C_{M}=\frac{M}{\frac{1}{2} \rho V^{2} S_{r e f} l_{r e f}} \\
C_{N \alpha}=\frac{C_{N\left(\alpha_{2}\right)-C_{N\left(\alpha_{1}\right)}}^{\alpha_{2}-\alpha_{1}}}{C_{M \alpha}}=\frac{C_{M\left(\alpha_{2}\right)-C_{M\left(\alpha_{1}\right)}}}{\alpha_{2}-\alpha_{1}}
\end{gathered}
$$

Table 1. BWB specification parameters 


\begin{tabular}{lll}
\hline $\begin{array}{l}\text { Aerodynamic } \\
\text { specification }\end{array}$ & inner wing & outer wing \\
AIRFOIL TYPE & NACA SC(2)-0710 & NACA SC(2)-0710 \\
SWEEP ANGLE & 38 & 38 \\
TAPER RATIO & 0.6557 & 0.2627 \\
ASPECT RATIO & 0.42 & 2.45 \\
WING AREA & $1000 \mathrm{~mm}^{2}$ & $2000 \mathrm{~mm}^{2}$ \\
MAXIMUM CHORD & $86.01 \mathrm{~mm}$ & $56.4 \mathrm{~mm}$ \\
MINIMUM CHORD & $56.4 \mathrm{~mm}$ & $14.819 \mathrm{~mm}$ \\
WING SPAN & $20.5 \mathrm{~mm}$ & $70 \mathrm{~mm}$ \\
\hline
\end{tabular}

3. WIND TUNNEL TESTING EXPERIMENTAI $25 \mathrm{~m} / \mathrm{s}$ and $35 \mathrm{~m} / \mathrm{s}$. The Reynolds number, using base SETUP

The tests are conducted using Low Speed Tunnel having test section area of $0.6 \mathrm{~m} \times 0.6 \mathrm{~m} \times 2 \mathrm{~m}$. It is a suction type tunnel, equipped with a 6-component balance, capable of measuring lift force, drag force, yawing moment, pitching moment, rolling moment and shearing force. Hence, a full model of BWB is used for the tests. The BWB planform has been manufactured using $\mathrm{CNC}$ machine with a size reduction of $1 / 6$. The tests are conducted at 3 different air speeds, i.e. $12 \mathrm{~m} / \mathrm{s}$, chord length as reference length, is of the order of $10^{5}$, and the Mach number ranges from 0.06 to 0.14 . Initially the value is calculated using six component balance of the wind tunnel set up at wind off mode and then taking the reading at wind- on mode condition at different angle from attack $0^{\circ}$ to $16^{\circ}$ angle of attack. The BWB aluminium model is placed in test section of wind tunnel at different angle of attack as shown in Fig. 8(a) to Fig.8(f).

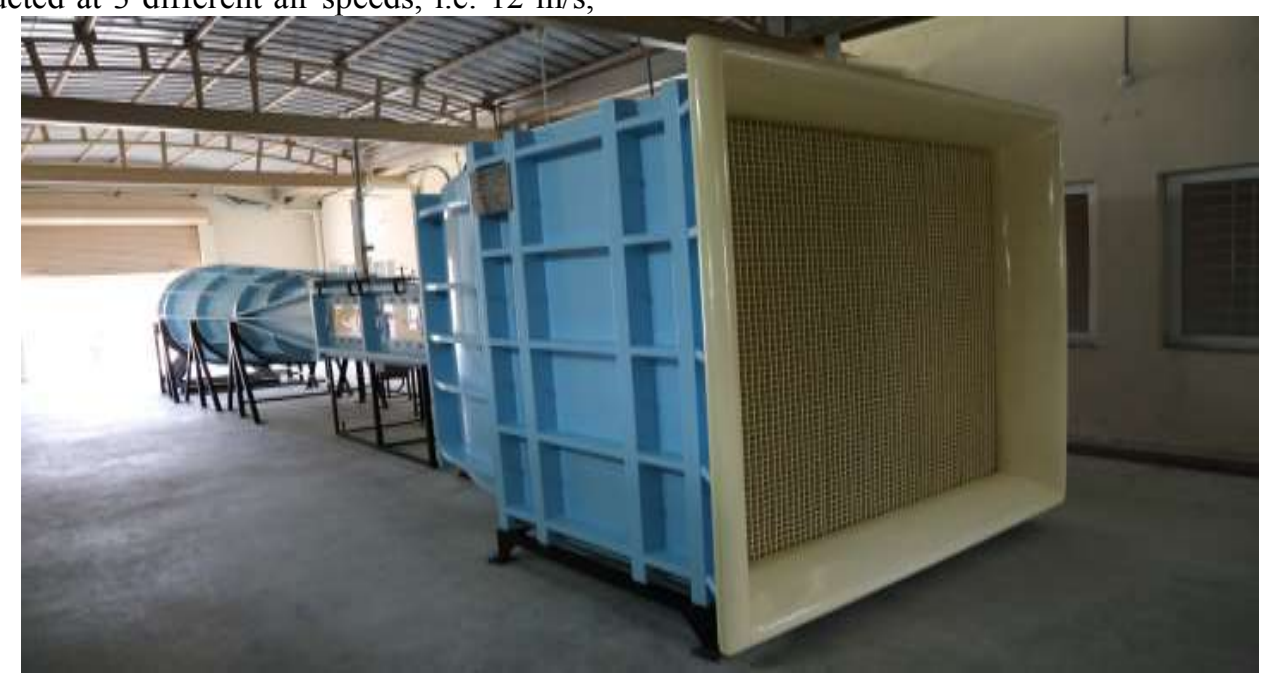

Fig.7 Low speed subsonic Wind Tunnel at Gitam University
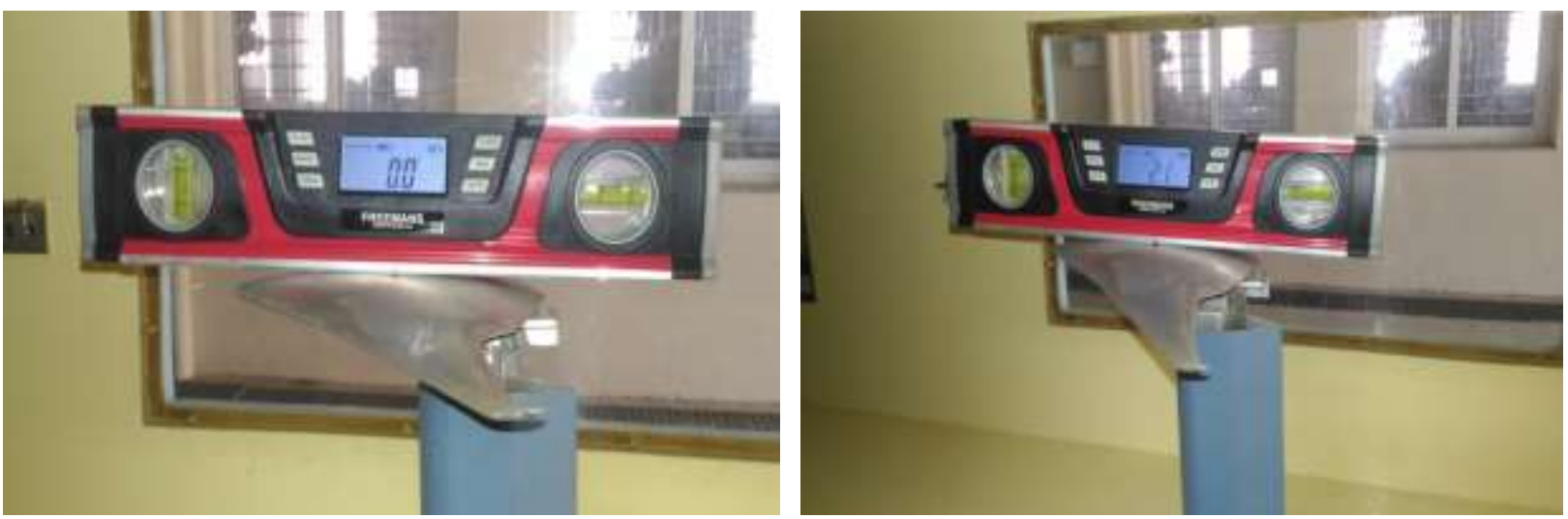

| Volume:4 | Issue: 11 | November| 2019 Journal Dol: https://doi.org/10.36713/epra2016 |www.eprajournals.com |129 | 
Fig.8 (a) BWB at $0^{\circ}$ angle of attack

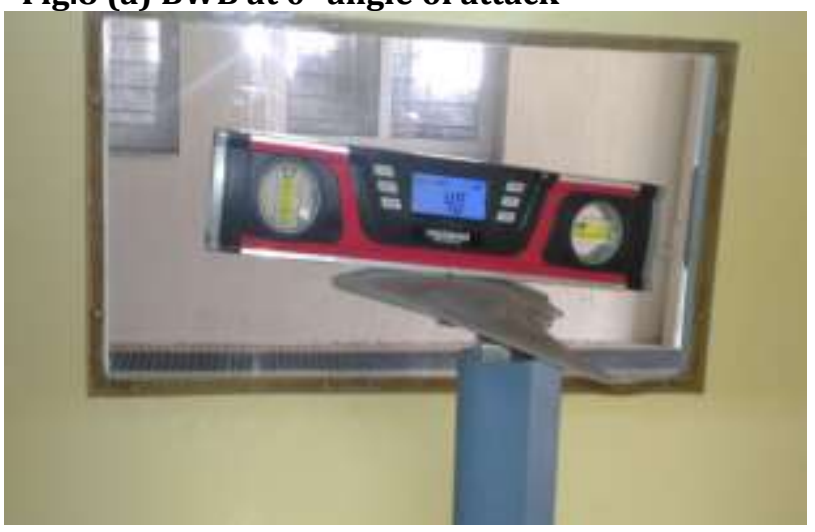

Fig.8 (c) BWB at $4^{\circ}$ angle of attack

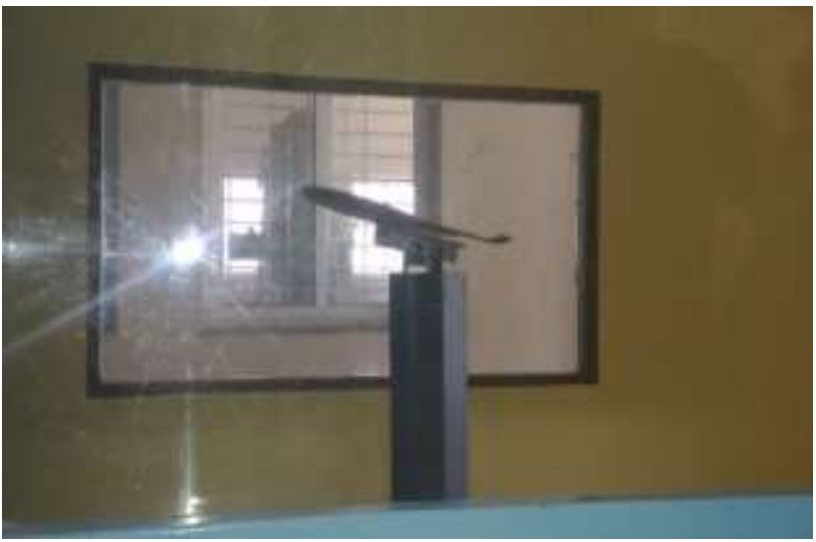

Fig.8 (e) BWB at $10^{\circ}$ angle of attack
Fig.8 (b) BWB at $2^{\circ}$ angle of attack

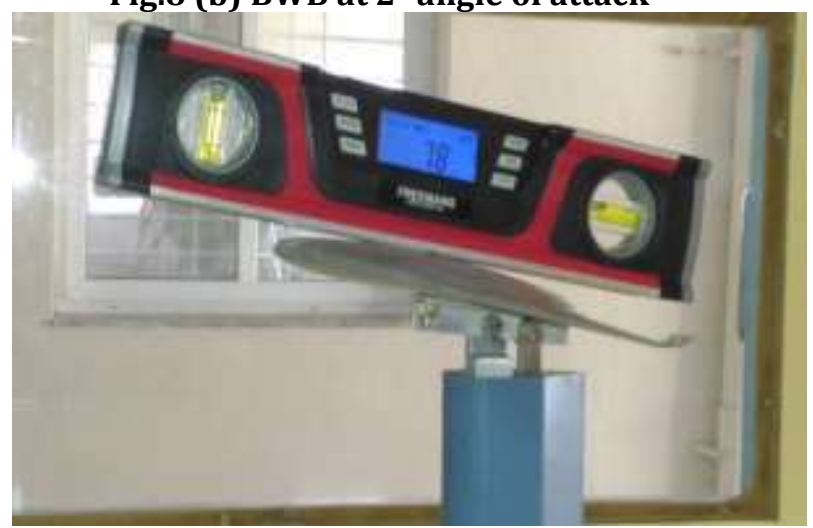

Fig.8 (d) BWB at $8^{\circ}$ angle of attack

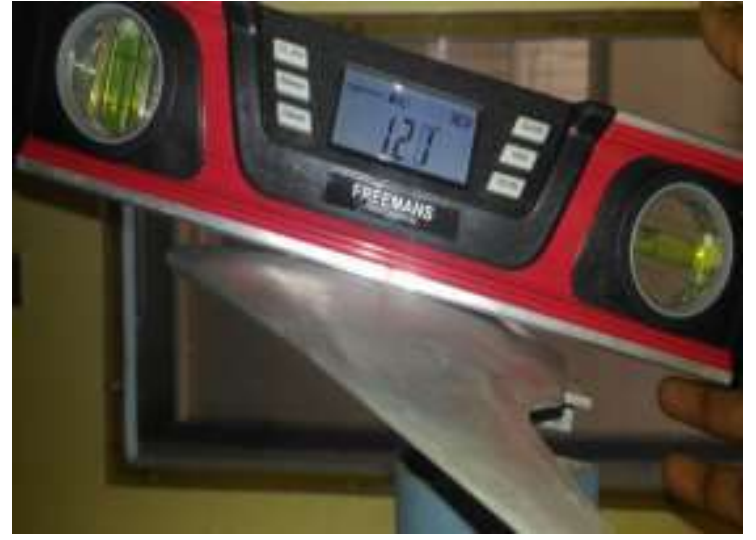

Fig.8 (f) BWB at $12^{\circ}$ angle of attack

3.1 Aerodynamic Performance Result output Parameters and Graph

Table 2. Wind Tunnel Six component balance output parameters at $400 \mathrm{rpm}(12 \mathrm{~m} / \mathrm{s})$ At 400 RPM

\begin{tabular}{rrrrrrrr}
\hline SI.NO & $\alpha$ & $\mathrm{L}$ & \multicolumn{1}{c}{$\mathrm{D}$} & \multicolumn{1}{c}{$\mathrm{C}_{\mathrm{L}}$} & \multicolumn{1}{c}{$\mathrm{C}_{\mathrm{D}}$} & $\mathrm{L} / \mathrm{D}$ & $\mathrm{Re}$ \\
$\mathbf{1}$ & 0 & -0.2222 & 0.056 & -0.00000099 & 0.000000249 & -3.96786 & $2.23 \times 10^{8}$ \\
$\mathbf{2}$ & 2 & 0.281 & 0.0314 & 0.000001252 & 0.000000139 & 8.949045 & $2.23 \times 10^{8}$ \\
$\mathbf{3}$ & 4 & 0.1166 & 0.0116 & 0.000000516 & 0.000000051 & 10.05172 & $2.23 \times 10^{8}$ \\
$\mathbf{4}$ & 6 & 0.357286 & 0.016286 & 0.000000072 & 0.000000072 & 21.9386 & $2.23 \times 10^{8}$ \\
$\mathbf{5}$ & 8 & 0.1544 & 0.0332 & 0.000000667 & 0.000000143 & 4.650602 & $2.23 \times 10^{8}$ \\
$\mathbf{6}$ & 10 & 0.163 & 0.021333 & 0.000000704 & 0.000000092 & 7.640625 & $2.23 \times 10^{8}$ \\
$\mathbf{7}$ & 12 & 0.1734 & 0.031 & 0.000000749 & 0.000000133 & 5.593548 & $2.23 \times 10^{8}$ \\
$\mathbf{8}$ & 14 & 0.3466 & 0.0396 & 0.000001497 & 0.000000171 & 8.752525 & $2.23 \times 10^{8}$ \\
$\mathbf{9}$ & 16 & 0.8532 & 0.118 & 0.000003686 & 0.000000509 & 7.230508 & $2.23 \times 10^{8}$ \\
\hline
\end{tabular}


Table 3. Wind Tunnel Six component balance output parameters at $800 \mathrm{rpm}(25 \mathrm{~m} / \mathrm{s})$

\begin{tabular}{cccccccc}
\hline \multicolumn{7}{c}{ At 800 RPM } \\
\hline SI.NO & $\alpha$ & $\mathrm{L}$ & $\mathrm{D}$ & $\mathrm{C}_{\mathrm{L}}$ & $\mathrm{C}_{\mathrm{D}}$ & $\mathrm{L} / \mathrm{D}$ & $\mathrm{Re}$ \\
$\mathbf{2}$ & 0 & 0.09625 & 0.08475 & 0.000000138 & 0.000000122 & 1.135693 & $3.92 \times 10^{7}$ \\
$\mathbf{3}$ & 2 & 0.623 & 0.054 & 0.000000906 & 0.000000078 & 11.53704 & $3.92 \times 10^{7}$ \\
$\mathbf{4}$ & 4 & 0.489 & 0.0498 & 0.000000704 & 0.000000071 & 9.819277 & $3.92 \times 10^{7}$ \\
$\mathbf{5}$ & 6 & 1.0255 & 0.065167 & 0.000001477 & 0.000000093 & 15.73657 & $3.92 \times 10^{7}$ \\
$\mathbf{6}$ & 8 & 0.6234 & 0.1022 & 0.000000897 & 0.000000147 & 6.099804 & $3.92 \times 10^{7}$ \\
$\mathbf{7}$ & 10 & 0.6432 & 0.1074 & 0.000000926 & 0.000000154 & 5.988827 & $3.92 \times 10^{7}$ \\
$\mathbf{8}$ & 12 & 0.7062 & 0.1318 & 0.000001017 & 0.000000189 & 5.358118 & $3.92 \times 10^{7}$ \\
$\mathbf{9}$ & 14 & 0.9176 & 0.1648 & 0.000001335 & 0.000000239 & 5.567961 & $3.92 \times 10^{7}$ \\
$\mathbf{1 0}$ & 16 & 1.6184 & 0.3124 & 0.000002354 & 0.000000454 & 5.180538 & $3.92 \times 10^{7}$ \\
\hline
\end{tabular}

Table 4. Wind Tunnel Six component balance output parameters at $1000 \mathrm{rpm}(35 \mathrm{~m} / \mathrm{s})$

\begin{tabular}{cccccccc}
\hline \multicolumn{7}{c}{ At 1000 RPM } \\
\hline SI.NO & $\alpha$ & $\mathrm{L}$ & $\mathrm{D}$ & $\mathrm{C}_{\mathrm{L}}$ & $\mathrm{C}_{\mathrm{D}}$ & $\mathrm{L} / \mathrm{D}$ & $\mathrm{Re}$ \\
$\mathbf{1}$ & 0 & 0.5925 & 0.067833 & 0.000000563 & 0.000000064 & 8.734644 & $4.83 \times 10^{7}$ \\
$\mathbf{2}$ & 2 & 0.89725 & 0.07475 & 0.000000852 & 0.000000071 & 12.00334 & $4.83 \times 10^{7}$ \\
$\mathbf{3}$ & 4 & 0.7986 & 0.0784 & 0.000000759 & 0.000000074 & 10.18622 & $4.83 \times 10^{7}$ \\
$\mathbf{4}$ & 6 & 1.7116 & 0.0962 & 0.000001616 & 0.00000009 & 17.7921 & $4.83 \times 10^{7}$ \\
$\mathbf{5}$ & 8 & 0.9854 & 0.1554 & 0.000000093 & 0.000000146 & 6.341055 & $4.83 \times 10^{7}$ \\
$\mathbf{6}$ & 10 & 1.0332 & 0.1682 & 0.000000982 & 0.000000159 & 6.142687 & $4.83 \times 10^{7}$ \\
$\mathbf{7}$ & 12 & 1.0996 & 0.22 & 0.000001045 & 0.000000209 & 4.998182 & $4.83 \times 10^{7}$ \\
$\mathbf{8}$ & 14 & 1.3352 & 0.2614 & 0.000001269 & 0.000000248 & 5.107881 & $4.83 \times 10^{7}$ \\
$\mathbf{9}$ & 16 & 2.2504 & 0.4618 & 0.000002153 & 0.000000441 & 4.873105 & $4.83 \times 10^{7}$ \\
\hline
\end{tabular}

\subsubsection{Aerodynamic Performance curves}

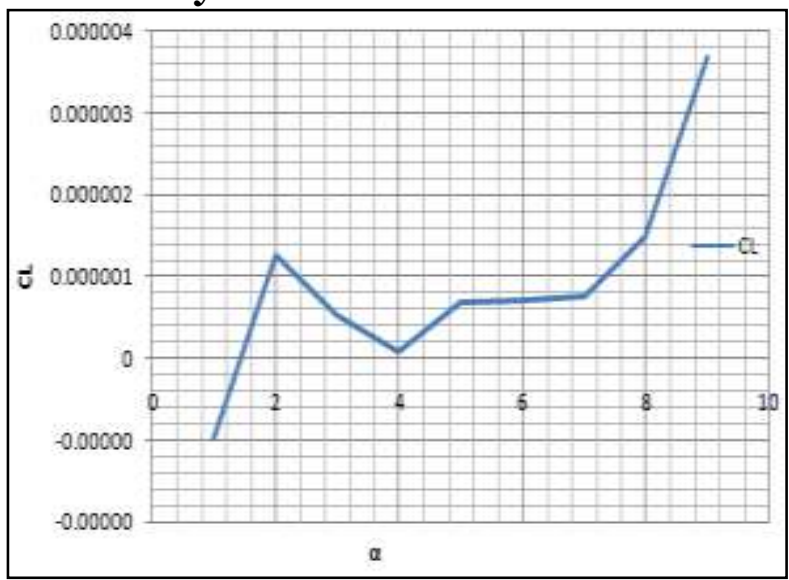

Fig. 9 (a) $C_{L}$ vs. $\alpha(400$ RPM)

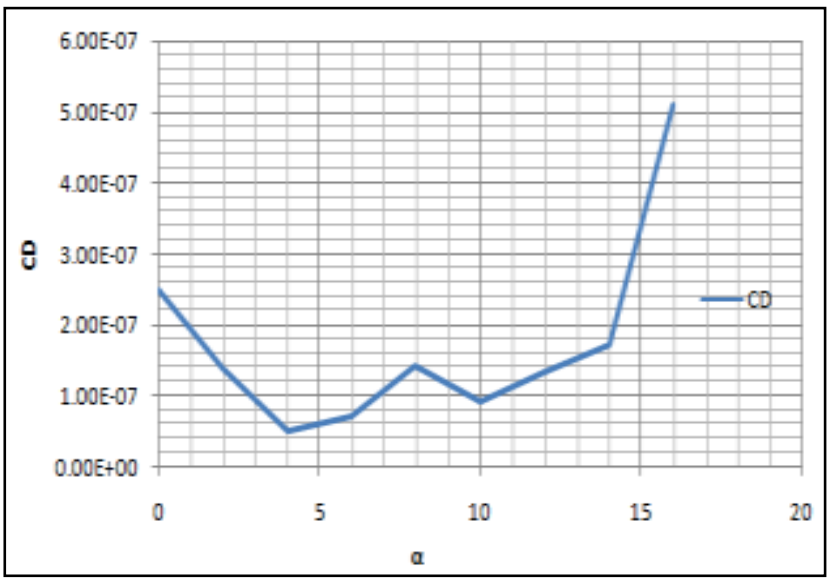

Fig. $9(b) C_{D}$ Vs. $\alpha(400$ RPM) 


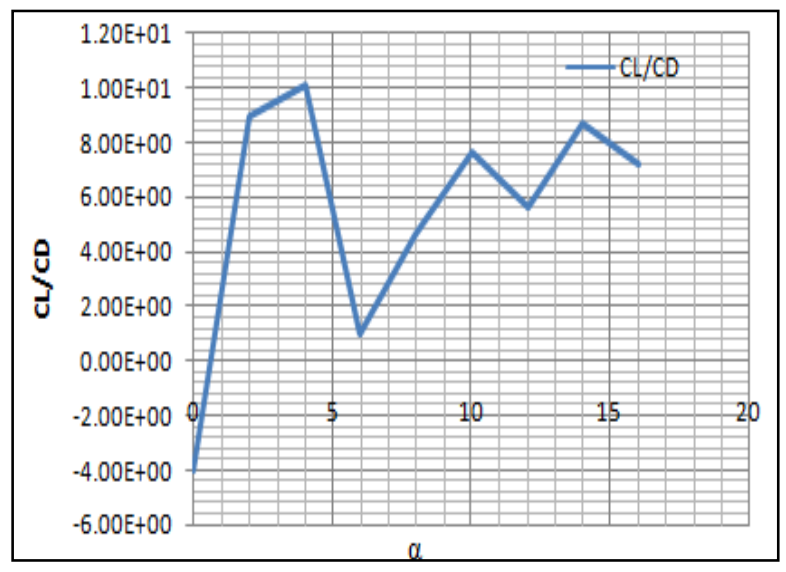

Fig. 9 (c) $C_{L} / C_{D}$ Vs. $\alpha(400$ RPM)

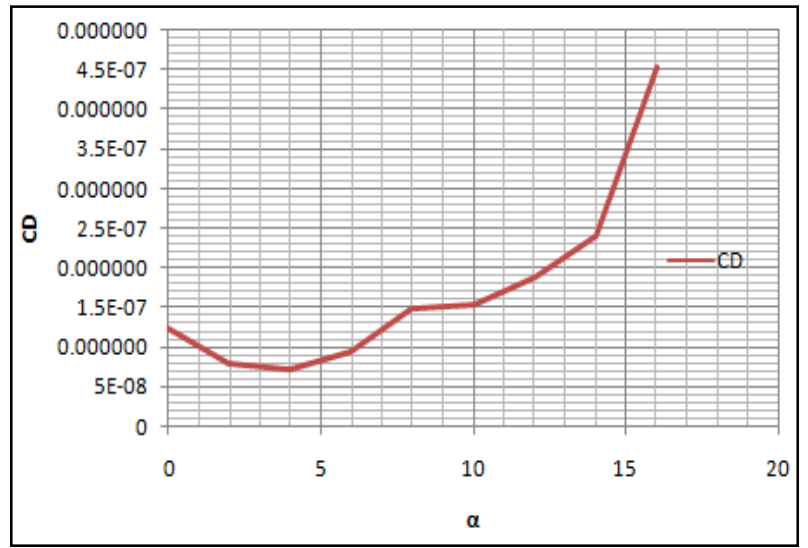

Fig. $9(\mathrm{e}) \mathrm{C}_{\mathrm{D}}$ vs. $\alpha(800$ RPM)

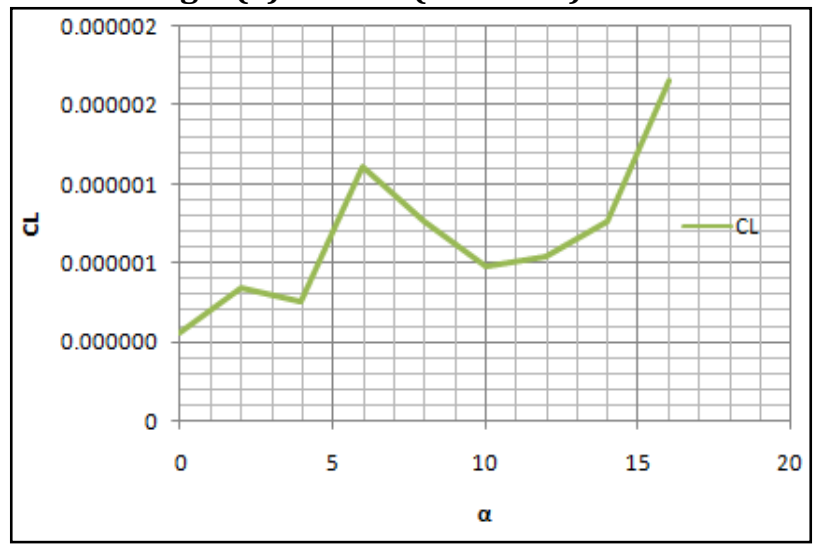

Fig. 9 (g) $C_{\mathrm{L}}$ vs. $\alpha(1000$ RPM )

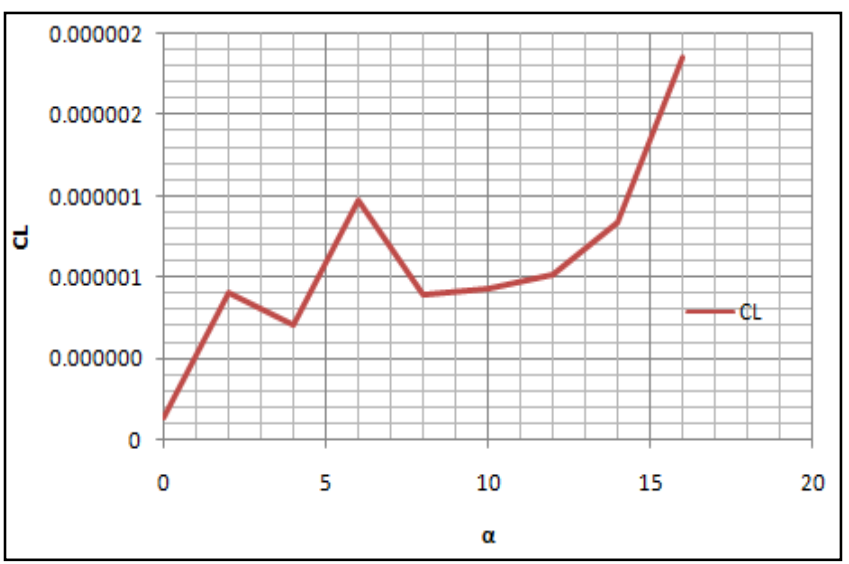

Fig. 9(d) $C_{L}$ vs. $\alpha(800$ RPM)

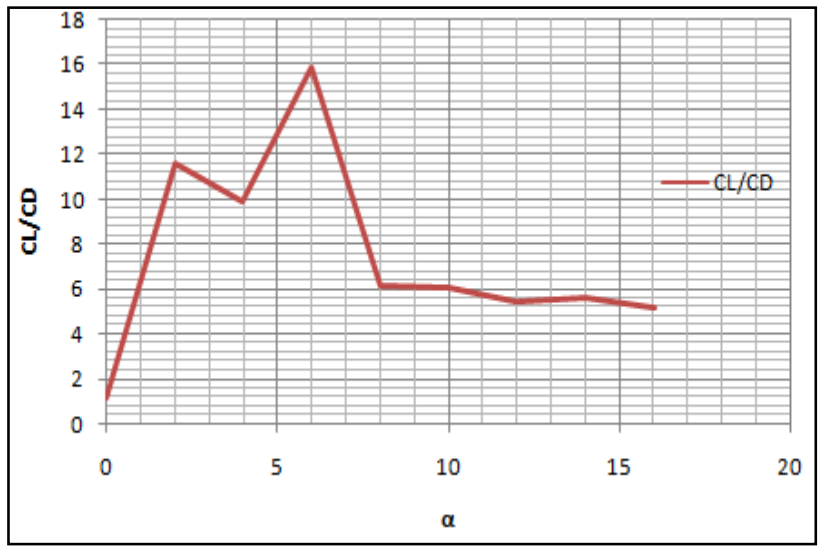

Fig. $9(f) C_{L} / C_{D}$ vs. $\alpha(800$ RPM $)$

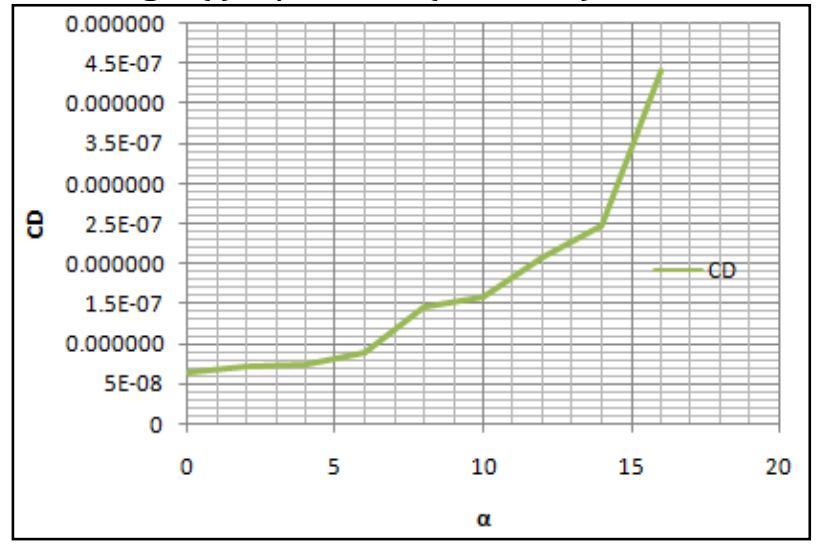

Fig. 9(h) CD vs. $\alpha$ (1000 RPM) 


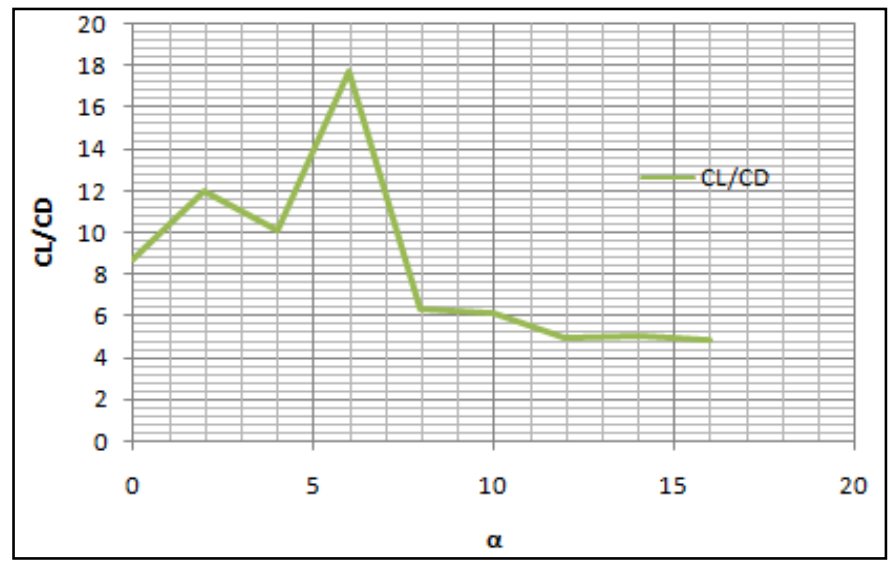

Fig. $9(i) C_{L} / C_{D}$ vs. $\alpha(1000$ RPM)

\subsubsection{Result Comparison Graph}

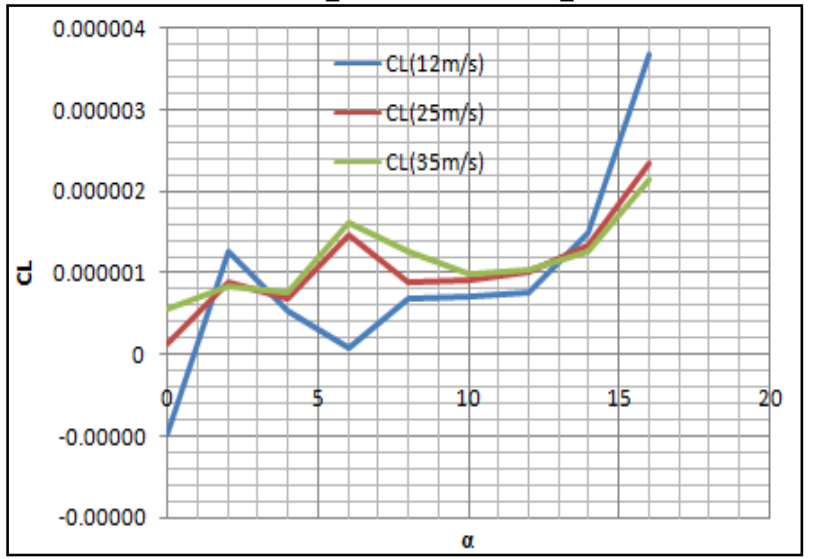

Fig. 10 (a) $C_{L}$ vs. $\alpha$

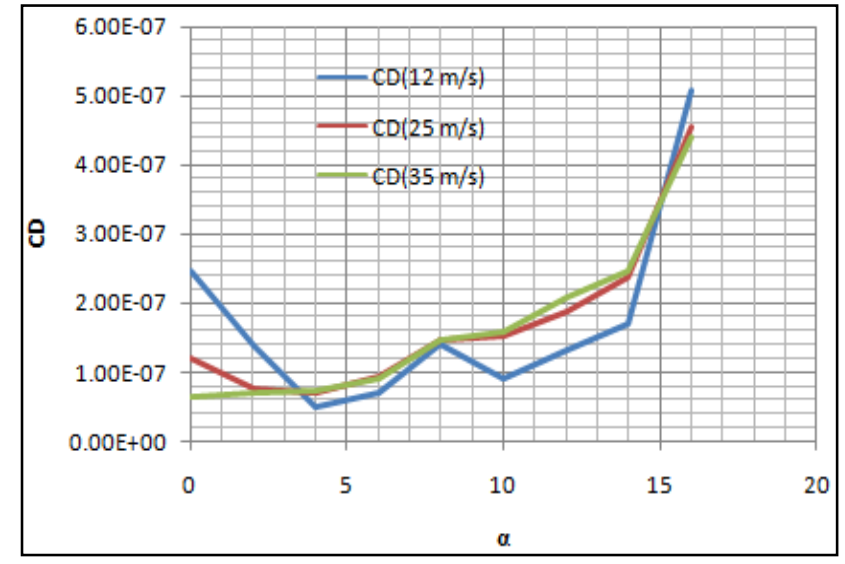

Fig. 10 (b) CD vs. $\alpha$

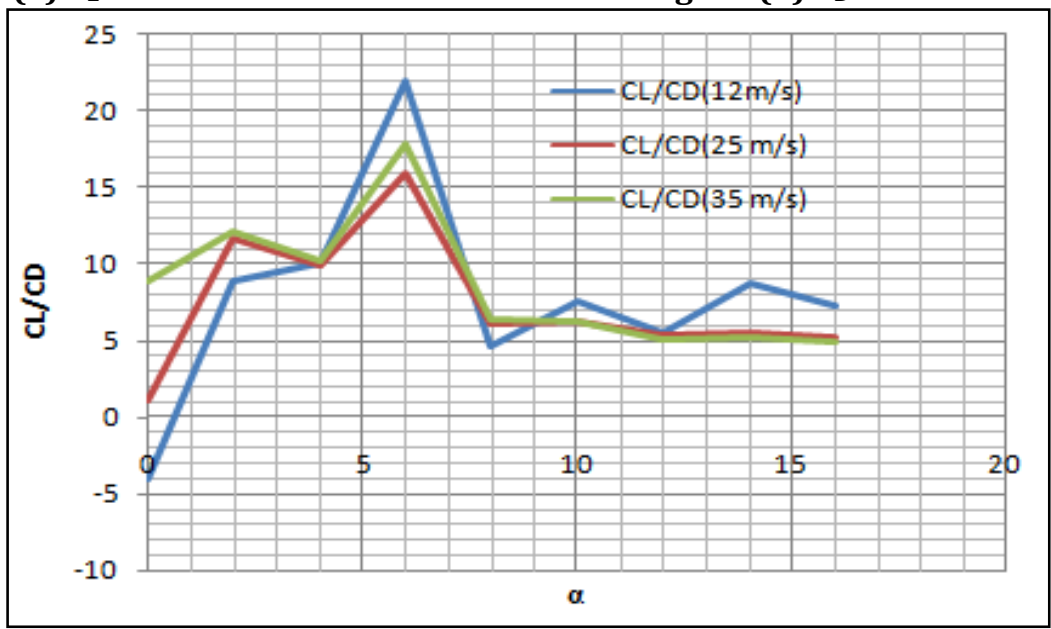

Fig. 10 (c) $C_{L} / C_{D}$ vs. $\alpha$

For the given free stream speed, the value of $\mathrm{C}_{\mathrm{L}}$ increases as the angle of attack increases as shown in Fig. 10 (a).With increase of velocity $C_{D}$ decreases initially then its increases as shown in fig.10 (b). The liftto-drag ratio (L/D) is a very significant parameter to pay attention to during the design process. It is the amount of lift generated by a wing or vehicle, divided by the aerodynamic drag it creates by moving through the air. A higher or more favorable L/D ratio is typically one of the major goals in aircraft design, The $\mathrm{L} / \mathrm{D}$ ratio is maximum at $6^{\circ}$ angle of attack as shown in Fig. 10 (c). A higher lift means that more weight is allowable, which in turn means a higher payload capacity (which is very important for transport aircraft). A lower drag value 
means less thrust will be required and hence lower fuel consumption (which is often the operators' largest operating cost).

\section{CONCLUSION}

The BWB is tested in wind tunnel to calculate the aerodynamic performance parameters which plays an important role in the design and sustainability of the Blended wing body aircraft. From experimental analysis we understand that, the BWB design configuration is much better compared to conventional aircraft. It has been found that the blended wing body can obtain better efficiency and high performance at subsonic speeds.. The lift generated by the blended wing body was found to be more than the conventional aircrafts. There was also a reduction in drag for the $\mathrm{BWB}$. One of the most significant differences between conventional aircrafts and the BWB is that the body or the fuselage of the BWB generates lift which was confirmed by the analysis of the center body. The BWB having a higher $(\mathrm{L} / \mathrm{D})$ ratio and the higher $\mathrm{L} / \mathrm{D}$ ratio the potential to become the future of commercial transport aircraft.

\section{REFERENCE}

1. Liebeck, R. H. (2004). Design of the Blended Wing Body Subsonic Transport. Journal of Aircraft ,Vol. 41, No. 1, pp. 10-25.

2. Wirachman Wisnoe,Rizal Effendy Mohd Nasir, Wahyu Kuntjoro,Aman Mohd Ihsan Mamat,Wind Tunnel Experiments and CFD Analysis of Blended Wing Body (BWB) Unmanned Aerial Vehicle (UAV) at Mach 0.1 and Mach $0.3,13^{\text {th }}$ International conference on aerospace sciences and aviation Technology.

3. Denisov, V. E., Bolsunovsky, A. L., Buzoverya N. P. and Gurevich, B. I (1998). Recent Investigations of the Very Large Passenger Blended-Wing-Body Aircraft. In: Proceedings 21st ICAS Congress, Melbourne, Australia, CD-ROM, Paper 98-4.10.2.

4. Md Akhtar Khan, Arjun Jagani, Computational Aerodynamic Analysis of Blended wing body MAV Design, IJRET, volume 5,Issue 11, November 2016,Page $-273-284$.

5. Martinez-Val, R. and Schoep, E. (2000). Flying Wing Verses Conventional Transport Airplane: The 300 Seat Case. In: Proceedings 22st ICAS Congress, Harrogate, United Kingdom, CD-ROM, paper 113.

6. Martinez-Val, R. and Hedo, J. M (2000). Analysis of Evacuation Strategies for Design and Certification of Transport Airplane. Journal of Aircraft, vol 37 no 3 pp. 440-447.

7. Qin, N., Vavalle, A., Moigne, A. L, Laban, M., Hackett, K., and Weinerfelt, P.(2002). Aerodynamic Studies for Blended Wing Body Aircraft. In: The 9th AIAA/ISSMO Symposium on Multidisciplinary Analysis and Optimization, no. AIAA 2002-5448.

8. Qin, N., Vavalle, A., Moigne, A. L., Laban, M., Hackett, K., and Weinerfelt, P.(2004). Aerodynamic Considerations of Blended Wing Body Aircraft. In: Progress in Aerospace Sciences, 40, 321-343.

9. Qin, N., Vavalle, A., and Moigne, A. L.(2005). Spanwise Lift Distribution for Blended Wing Body Aircraft. Journal of Aircraft, 42, 356-365.
10. Siouris, S., and Qin, N., (2007). Study of the Effects of Wing Sweep on the Aerodynamic Performance of a Blended Wing Body Aircraft. Journal of Aerospace Engineering, 221(1), 47-55.

11. Potsdam, M. A., Page, M.A., and Liebeck, R. H. (1997). Blended Wing Body Analysis and Design. In: 15th AIAA Applied Aerodynamics Conference, Atlanta, Georgia, no. AIAA 1997-2317.

12. Roman, D., Allen, J. B., and Liebeck, R. H. (2000): Aerodynamic Design Challenges of the Blended-WingBody Subsonic Commercial Transport. In: 18th AIAA Applied Aerodynamics Conference, Denver, Colorado, United States, no. AIAA-200O- 4335.

13. Bradley, K.(2004). A Sizing Methodology for the Conceptual Design of Blended-Wing-Body Transports. Tech. rep., NASA/CR2004-213016

14. Nimeesha, Kuntawala, B., Hicken, J.E., and David, W. Z. (2011). Preliminary Aerodynamic Shape Optimization of a Blended Wing-Body Aircraft Configuration, AIAA201 1-642.

15. Lyu. Z., and Joaquim, R., Martins, R. A., (2015). Aerodynamic Design Optimization Studies of a BlendedWing-Body Aircraft, Journal of Aircraft 32-6, 19511970.

16. Roysdon, F. and Mahmood Khalid, (2011). BlendedWing-Body Lateral-Directional Stability Investigation using 6DOF Simulation, AIAA, 2011-1563 Infotech@Aerospace 201129 - 31 March 2011, St. Louis, Missouri. 16. Struber, H. and Hepperle, M., (2016). Aerodynamic Optimization of a Flying Wing Transport Aircraft. New Results in Numerical and Experimental Fluid Mechanics 92, pp 69- 76.

17. Meheut, M., Grenon, R., Carrier, G., Defos, M. and Duffau, M., (2009). Aerodynamic Design of Transonic Flying Wing Configurations. In:KATnet II: Conference. On \Key Aerodynamic Technologies, Bremen, Germany, 12-14th May.

18. Osterheld, O., Heinze, W. and Horst, P., (2001). Preliminary Design of a Blended Wing Body Configuration Using the Design Tool Pr ADO. In: Proceedings of the CEAS Conference on Multidisciplinary Aircraft Design and Optimization, Cologne.

19. Peigin, S. and Epstein, B., (2006). Computational Fluid Dynamics Driven Optimization of Blended Wing Body Aircraft, AIAA Journal, vol44 no1 1 pp. 2736-2745.

20. Diedrich, J., Hileman, D., Tan, K., Willcox and Spakovszky, Z.(2006). Multidisciplinary Design and Optimization of the Silent Aircraft. In: 44th AIAA Aerospace Sciences Meeting and Exhibit, Reno, Nevada, United States, no. AIAA 2006-1323.

21. Chittick, $R$ and Martins, J. R. R. A.(2008). AeroStructural Optimization Using Ad-joint Coupled PostOptimality Sensitivities, Structural and Multidisciplinary Optimization, vols6, pp.59-77.

22. Syed, H. M., Hameed, M. S. and Manarvi, I.A. (2011): A Review of Swept and Blended Wing Body Performance Utilizing Experimental, $F E$ and Aerodynamic Techniques. International Journal of Recent Research and Applied Studies.

23. Wan, T. and Yang, H.: Aerodynamic Performance Investigation of A Modern Blended-Wing-Body Aircraft under the Influence of Heavy Rain Condition, International Congress of the Aeronautical Sciences. 
24. Lehmkuehler, K., Wong, K. C. and Verstraete, D., (2012). Design and Test of a UAV Blended Wing Body Configuration, International Congress of the Aeronautical Sciences.

25. Pineda, J. S., and Ceron-Munoz, H. D., (2014). Aerodynamic Interference of Wing Top and Wing Devices on BWB Model, Congress of the International Council of the Aeronautical Sciences.

26. Naidu, K. S., G. Shruthi Keerthi, G., Nikhil B.(2016). CFD Analysis of Blended Wing Body and B2 Wing, International Journal of Engineering Sciences $\mathcal{E}^{\circ}$ Research Technology, Thomson Reuters Endnote. 